\title{
АНАЛИЗ ОСОБЕННОСТЕЙ И РИСКОВ РАЗВИТИЯ ЦИФРОВИЗАЦИИ И ЕЕ ПОСЛЕДСТВИЙ ДЛЯ ГОСУДАРСТВА
}

\author{
(c) 2021 Бакулина Анна Александровна \\ доктор экономических наук, профессор, \\ профессор кафедры государственного управления МГИМО МИД России \\ Московский Государственный Институт Международных Отношений, Россия, Москва \\ E-mail: anbakdoc@mail.ru \\ (c) 2021 Чаленко Николай Николаевич \\ преподаватель кафедры государственного управления МГИМО МИД России \\ Московский Государственный Институт Международных Отношений, Россия, Москва \\ E-mail:n_chili@mail.ru
}

(c) 2021 Солодовникова Кристина Игоревна

главный специалист Отдела оценки ООО «Центр оценки собственности «МОРФ», Россия, Москва

E-mail: kristina.solodovnikova@inbox.ru

Стремительное распространение цифровых технологий разрушает устоявшиеся модели производства и торговли, создавая как возможности, так и проблемы для устойчивого развития.

Целью настоящей научно-исследовательской статьи является систематизация методов и подходов по выявлению рисков государства и общества в условиях глобальной цифровизации.

Для реализации поставленной цели в работе проведен анализ особенностей развития цифровизации и ее последствий для государства.

Цифровые технологии несут не только новые возможности, но и новые риски. Эти риски нуждаются в систематизации, классификации, оценки их влияния на экономику и общество, а также разработки концепции и инструментов управления ими. Защита российских компаний, граждан и юридическая, и технологическая - это сейчас одно из основных тем цифровой трансформации экономики. Необходимо найти компромисс между работой с большими массивами данных и конфиденциальностью информации. Задача регулятора и политиков - обеспечить гарантии развития цифровизации в России на высоком технологическом уровне и максимально снизить риски для государства и общества.

Ключевые слова: цифровая экономика, экономическая безопасность, программа мониторинга рисков, управления цифровыми рисками.

Стремительное развитие цифровых технологий с начала 21 века обусловило формирование государственной политики стимулирования процессов цифровизации национальных экономик и всех сегментов общественно-социальных отношений. На межгосударственном, национальных и региональных уровнях реализуются инициативы внедрения цифровых технологий. Процесс цифровизации включает множество элементов, которые могут реализовываться в том числе различно по времени, охвату и глубине проникновения технологий.

Происходящий прогресс в сферах интернет вещей, анализа больших данных, облачных вычислений и искусственного интеллекта определит масштабные инновации, принципиально меняющие государственное управление и общество, условия хозяйственной жизни в следящие десятилетия. Правительства стран вынуждены определить направления поддержки экспериментальной и новаторской деятельности, обращая внимание при этом на последствия возможных рисков, обеспечивая информационную безопасность, конфиденциальность данных и занятость населения.

Широкое распространение получит интернет вещей, наряду с людьми, организациями и информационными ресурсами агрегирует объекты восприятия и обработки цифровой информации. Такая инфраструктура будет производить значительные объемы данных, имеющие практическое применение в производственной 
сфере, оптимизируя процессы, и в цепочках распределения товаров и услуг, улучшая качество жизни людей [2].

Анализ больших данных (технология BigData) позволит людям извлекать полезные данные из массивов различной информации, лучше анализировать и прогнозировать события и явления, поведенческие черты, совершенствовать решения в управлении и политике, при этом увеличится потребность в соответствующих специалистах, обладающих аналитическими, техническими, методическими и вычислительными компетенциях, а также инфраструктура сетей с высокой пропускной способностью.

Облачные и аналогичные архитектуры обеспечат доступ к масштабируемым вычислительным ресурсам, что позволит получать в интернете гибкие информационные услуги, снижая издержки на инфраструктуру ИКТ, делая их доступными для малого и среднего бизнеса.

Искусственный интеллект окажет помощь в принятии разного рода решений, при этом потребуется формирование новых образовательных программ по подготовке специалистов соответствующей квалификации в области программирования и использования больших комплексов данных для разработки алгоритмов.

Передовые цифровые технологии способствуют достижению целей устойчивого развития, в том числе посредством развития таких отраслей, как производство точной агротехники, государственное управление, здравоохранение, образование, «умный транспорт», «умный город».

В настоящее время существует значительный объем теоретических и эмпирических аргументов, подтверждающих достоверность данных выводов. Аналитические материалы, ежегодно публикуемые по результатам исследований влияния цифровизации на государство и общество, проводимых специализированными учреждениями, институтами и компаниями на базе макроэкономических показателей различных стран, обозначают положительное влияние цифровизации на уровень производительности, отражаемый в статистике [1].

В эпоху цифровой экономики информация становится одним из факторов производства, как ранее в индустриальный период, таковым являлись труд и капитал. Заметен рост показателя производительности при внедрении цифровых технологий в производственную сферу и увеличение деловой активности. Цифровизация влияет на рост производительности несколькими способами:

- снижение операционных издержек, что особенно актуально для сегмента финансовых технологий. Финансовые операции, связанные с посещением банковских учреждений, теперь можно завершить за считанные секунды с помощью мобильного телефона;

- сокращение информационной асимметрии и оптимизация спроса и предложения. Система, созданная крупными ИТ-компаниями, позволяет мелким поставщикам получать доступ к огромной «базе данных потребителей» (технологии Big Data). Анализ больших данных также определяет потребительские предпочтения и облегчает целевое предоставление услуг;

- повышение эффективности производства за счет автоматизации, поскольку в результате сокращаются производственные циклы, повышается качество и надежность продукции.

Цифровизация создала миллионы рабочих мест в новых секторах. Быстрорастущий сегмент электронной коммерции и экономика совместного потребления стали движущей силой создания рабочих мест, при этом миллионы рабочих мест были потеряны в результате цифровой революции. Негативное влияние цифровизации на уровень занятости населения в большей степени проявляется в промышленности, в то время как занятость в сфере услуг остается довольно ограниченной. Например, ведущая ИТ-компания Foxcom заменила 60000 сотрудников на 40000 роботов. В сегменте услуг розничные продажи наиболее чувствительны к изменениям, связанным с цифровизацией. Тем не менее, несмотря на популярность и масштабное внедрение инструментов электронной коммерции, количество работников, занятых в розничной торговле, в целом остается стабильным.

Сочетая две противоположные тенденции, необходимо сделать вывод, что чистый эффект цифровизации на занятость населения можно охарактеризовать как положительный. Хотя рост ВВП в мировой экономике последние годы замедлился, общий уровень занятости в развитых странах продолжает расти из-за перехода к более трудоемким моделям обслуживания.

Цифровизация оказывает существенное влияние на структуру рынка, которое оценивается в разрезе элементов [4]:

- сокращение посредников. Цифровизация 
сократила количество распределений уровней, позволяя напрямую связывать спрос и предложение через специализированные цифровые платформы;

- увеличение количества малых предприятий в традиционных отраслях.

В финансово-кредитной сфере кредиты интернет-платформы («Р2P») также демонстрируют значительный рост. Функционально Р2Р-платформы отличаются от традиционных кредитных учреждений - они больше выступают в качестве информационных посредников. В их обязанности входит сбор информации, рассмотрение заявок на получение ссуды, обеспечение обмена информацией и отбор кандидатов и кредиторов. Такие платформы в основном получают деньги от розничных инвесторов. Помимо ограниченного доступа к заемным средствам и ограничения процентных ставок, а также кредитования банками, в первую очередь, крупных корпораций и государственных предприятий, были созданы благоприятные условия для роста платформ Р2Р.

Сегмент микрозаймов от онлайн-банков также находится на подъеме. На современном финансовом рынке существует три категории микрокредитования: кредиты для операторов интернет-магазинов, потребительские кредиты для пользователей интернет-магазинов и небольшие кредиты для домашних хозяйств, находящихся в затруднительном положении, в основном из сельской местности. В отличие от традиционных банков, интернет-банки в основном обрабатывают микрокредиты, обрабатывают большие данные с электронных торговых платформ и оценивают кредитный риск.

Уникальное сочетание информационных технологий и финансов может оказывать существенное одновременное влияние на всю финансовую систему в деятельности крупных компаний, работающих в сфере услуг. Поставщики услуг онлайн-платежей принимают средства от банков, вкладывают их в виде межбанковских депозитных сертификатов или микрокредитов, в результате чего условия кредитования и погашения преобразуются. За фактическим движением средств трудно следить, поскольку операционные компании действуют за рамками надзорных органов.

Тесная интеграция различных сегментов цепочки создания добавленной стоимости может способствовать распределению рисков в систе- ме финансовых услуг, увеличивая потери в случае рецессии. В интегрированных закрытых финансовых системах сложность отслеживания транзакций возросла. Такая модель не может обеспечить адекватный контроль над базами данных или обмен данными между участниками рынка и надзорными органами.

Помимо обеспечения финансовой стабильности, развитие финансовых технологий будет также сосредоточено на других вопросах: безопасность данных, кибербезопасность, защита потребителей, содействие конкуренции, борьба с отмыванием денег и финансированием терроризма станут неотъемлемой частью развития финансовых технологий и системы регулирования.

Прогнозируется, что цифровизация мировой экономики будет продолжаться быстрыми темпами из-за огромного сообщества пользователей Интернета, растущего качества цифровой инфраструктуры и спроса на цифровые продукты. Локомотивом следующей фазы цифровизации будет бизнес - более широкое внедрение цифровых технологий ожидается в бизнес-процессах и государственном секторе.

Несмотря на рост производительности, связанный с цифровизацией, экономический рост в развитых странах будет продолжать замедляться. Наряду с ростом доходов темпы экономического роста в стране, естественно, будут замедляться по мере приближения к технологической границе.

Цифровизация может привести к дальнейшей потере рабочих мест в промышленном секторе экономики, но влияние на рынок труда остается ограниченным. С внедрением технологий автоматизации производства спрос на низкоквалифицированную рабочую силу уменьшится, но ожидается, что в сфере услуг будут созданы миллионы рабочих мест. Если бывшие промышленные рабочие смогут переучиться и найти работу в другой области, например, в сегменте услуг, общий рост занятости останется положительным, и важно, чтобы процесс сокращения доли трудоспособного населения в развитых странах продолжал способствовать снижению емкости рынка труда.

Цифровизация также может привести к большей поляризации рынка труда, создает неравные выгоды для участников рынка труда в зависимости от характера выполняемых задач. Работники со средними квалификационными требованиями наиболее уязвимы в том случае, 
если их функционал и должностные обязанности состоят из выполнения задач, которые можно легко автоматизировать. Напротив, внедрение ИКТ дополняет высококвалифицированную рабочую силу. Влияние ИКТ на занятость обычно нейтрально для определенных типов низкоквалифицированных работников определенной профессии, например, таких как медицинские сестры. Следовательно, цифровизация может привести к поляризации рынка труда с ростом неравенства в доходах и более высокого уровня занятости среди высококвалифицированной и низкоквалифицированной рабочей силы по сравнению с «сокращающейся серединой».

Широкое распространение искусственного интеллекта увеличивает риск снижения занятости. В настоящее время искусственный интеллект находит лишь ограниченное практическое применение, однако этот тип технологий быстро развивается. Технологии машинного обучения, которые являются подмножеством технологий искусственного интеллекта, уже внедряются в финансовом секторе.

Современные тенденции цифровизации обуславливают необходимость исследования рисков новой реальности, выработку условий и технологий управления факторами, определяющими успех и результативность процессов цифровой экономики. Российский экономист-исследователь проблем четвертой промышленной революции профессор А.В.Бабкин выделяет ряд направлений, определяющих технологическое, инновационное и экономическое развитие [5]:

1. дигитализация (digitalization) в виде расширения инновационных цифровых технологий и синергии физического и виртуального миров в едином кибернетическом пространстве;

2. возвращение обособленных структур компаний-производителей мировых товаров из регионов с дешевой рабочей силой в развитые страны в результате развития и преимуществ дигитализации ввиду значительного сокращения транзакционных издержек, в том числе на оплату труда;

3. необходимость создания новых форм и способов производства, модификация спроса на товарных рынках, реализация международных инновационных проектов.

\section{Вывод.}

Таким образом, цифровизация приносит не только экономические выгоды, но и риски. Дуализм проявляется в том, что с одной стороны, цифровизация может повысить производительность труда, помочь сбалансировать экономику и создать рабочие места в новых секторах. С другой стороны, цифровизация может оказать негативное влияние на традиционные секторы экономики с точки зрения сокращения занятости, особенно среди работников средней квалификации в обрабатывающей промышленности. Внедрение ИКТ в финансовом секторе повышает эффективность финансовых услуг и способствует повышению финансовой интеграции населения, но угрожает финансовой стабильности и усложняет работу финансового надзора и регулирования. В конечном счете цифровизация создаст новые стимулы для роста, но их будет недостаточно, чтобы обратить вспять замедление мировой экономики.

\section{Библиографический список}

1. Анализ текущего состояния развития цифровой экономики в России. URL: https://iis.ru/wp-content/ uploads/2020/12/decarussia2018rus.pdf

2. Интернет вещей: приготовьтесь к подключенному государству https://json.tv/tech_trend_find/internetveschey-prigotovtes-k-podklyuchennomu-gosudarstvu-20160405080900

3. Цифровая трансформация экономики и промышленности: проблемы и перспективы / под ред. Д-ра экон. Наук, проф. А. В.Бабкина. - спб.: Изд-во Политехн. Ун-та, 2017. - 807 с.

4. Что такое цифровая экономика? Тренды, компетенции, измерение. URL: https://www.hse.ru/ data/2019/04/12/1178004671/2\%20\%D0\%A6\%D0\%B8\%D1\%84\%D1\%80\%D0\%BE\%D0\%B2\%D0\%B0\%D1\%8F_\%D1 \%8D\%0\%BA\%D0\%BE\%D0\%BD\%D0\%BE\%D0\%BC\%D0\%B8\%D0\%BA\%D0\%B0.pdf

5. Цифровая трансформация экономики и промышленности: проблемы и перспективы / под ред. Д-ра экон. Наук, проф. А. В.Бабкина. - спб.: Изд-во Политехн. Ун-та, 2017. - 807 с. 